Check for updates

Cite this: RSC Adv., 2017, 7, 36714

\title{
Synthesis and characterization of a biodegradable polyaspartic acid/2-amino-2-methyl-1-propanol graft copolymer and evaluation of its scale and corrosion inhibition performance
}

\begin{abstract}
Shuchen Shi, ${ }^{a}$ Yufeng $\mathrm{Wu}^{\text {ab }}$ Yueyan Wang, ${ }^{\mathrm{a}}$ Jing $\mathrm{Yu}^{\mathrm{a}}$ and Ying $\mathrm{Xu}$ (D) *ac
Herein, a novel polyaspartic acid derivative, polyaspartic acid/2-amino-2-methyl-1-propanol graft copolymer (PASP/AMP), was synthesized via a ring-opening reaction using polysuccinimide (PSI) and 2amino-2-methyl-1-propanol (AMP). The structure of PASP/AMP was characterized via ${ }^{1} \mathrm{H}$ NMR and FTIR. Its scale and corrosion inhibition performances were investigated via static and weight loss tests, respectively. Additionally, its biodegradability was assessed by measuring its chemical oxygen demand. The influence of PASP/AMP on scale deposition was observed via scanning electron microscopy (SEM) and X-ray powder diffraction (XRD). The maximum scale inhibition efficiency of $100 \%$ for PASP/AMP against $\mathrm{CaCO}_{3}, \mathrm{CaSO}_{4}$, and $\mathrm{Ca}_{3}\left(\mathrm{PO}_{4}\right)_{2}$ was achieved at the concentrations of 1,4 , and $14 \mathrm{mg} \mathrm{L}^{-1}$, respectively. Its corrosion inhibition efficiency for carbon steel is close to $28 \%$ at $24 \mathrm{mg} \mathrm{L}^{-1}$. The degradation rate of PASP/AMP could reach up to $65 \%$ within 28 days. According to the SEM images and XRD spectra, the scale deposits become irregular and distorted in shape, which can easily be dispersed by flowing water. This study demonstrates that PASP/AMP as a biodegradable inhibitor exhibits better scale and corrosion inhibition performances as compared to PASP and shows promising prospect for application.
\end{abstract}

Received 20th June 2017 Accepted 14th July 2017

DOI: $10.1039 / c 7 r a 06848 d$

rsc.li/rsc-advances corrosion, they are unstable and easily result in water pollution, which restrict their applications. ${ }^{14-16}$ Since the permissible limits for inhibitors are decreasing due to environmental concerns, the development of non-phosphorus, efficient, green degradable inhibitors has been a current research topic. ${ }^{17-19}$

Polyaspartic acid (PASP), which contains carboxyl groups, tends to combine with metal ions at different $\mathrm{pH}$ values, possesses good chelating ability, and has been proven to be a representative scale inhibitor. ${ }^{20-22}$ Moreover, PASP is easily degraded by microorganisms and fungi into environmentally friendly products. ${ }^{23}$ Thus, as a nontoxic and degradable green inhibitor, PASP possesses good scale inhibition ability for $\mathrm{CaCO}_{3}$ and $\mathrm{CaSO}_{4}$. However, since it only contains one functional group, carboxyl, its scale inhibition ability against $\mathrm{Ca}_{3}\left(\mathrm{PO}_{4}\right)_{2}$ and corrosion inhibition properties are not prominent. For further improvement of its scale and corrosion inhibition performance, several methods have been conducted for the modification of PASP. A polyaspartic derivative, SerPASP, was obtained by Chen et al., which showed better scale inhibition and dispersion performance than PASP. Gao et al. synthesized PASP-SEA-ASP and found that the copolymer exhibited an outstanding corrosion inhibition performance for seawater. A PASP/urea graft copolymer was prepared by Zhang et al., and its scale inhibition performance against $\mathrm{Ca}_{3}\left(\mathrm{PO}_{4}\right)_{2}$ was improved. ${ }^{24-26}$ Although these studies have improved the

${ }^{a}$ College of Chemistry and Chemical Engineering, Henan University, Kaifeng 475004, China

${ }^{b}$ Henan Engineering Research Center of Industrial Circulating Water Treatment, Kaifeng 475004, China

'School of Pharmaceutical Sciences, Zhengzhou University of Industrial Technology, Zhengzhou 451150, China 
scale and corrosion inhibition performance of PASP to some extent, there still remains many problems such as the degradation behavior of the copolymer. To obtain a biodegradable inhibitor with outstanding comprehensive properties, it is necessary to introduce new functional groups into the side chain of PASP. ${ }^{27}$

2-Amino-2-methyl-1-propanol (AMP) is a low-cost compound with an uncomplicated structure. Moreover, it contains one main functional group, hydroxy, which would contribute to improving the scale inhibition performance of PASP. In this research, a novel hydroxylation PASP derivative, polyaspartic acid/2-amino-2-methyl-1-propanol graft copolymer (PASP/AMP), was obtained via a ring-opening reaction using polysuccinimide (PSI) and AMP as raw materials. The structure of PASP/AMP was characterized via ${ }^{1} \mathrm{H}$ NMR and FTIR. Thermogravimetric analysis was conducted to examine the stability of PASP/AMP. Static and weight loss tests were carried out to simultaneously investigate the scale and corrosion inhibition performance of PASP/ AMP. Moreover, a biodegradation experiment on PASP/AMP was conducted. The structures of the scale in the absence and presence of PASP/AMP were observed via scanning electron microscopy (SEM) and X-ray powder diffraction (XRD).

\section{Experimental}

\subsection{Reagents and instruments}

Maleic anhydride, ammonium ferrous sulfate, ammonium molybdate, and antimony potassium tartrate were purchased from Kemiou Chemical Reagent Co., Ltd (China). Urea, ascorbic acid, 1,10-phenanthroline monohydrate, and ethylenediaminetetraacetic acid disodium salt were supplied by Tianjin No. 1 Chemical Reagent Factory (China). 2-Amino-2methyl-1-propanol and Eriochrome Black $\mathrm{T}$ were obtained from Aladdin Chemical Reagent Co., Ltd (China).

The instruments used include an AVANCE 400 nuclear magnetic resonance spectrometer (Switzerland), a VERTEX 70 Fourier transform infrared spectrometer (Germany), a $723 \mathrm{~N}$ grating spectrophotometer (China), an RCC-III rotary coupon corrosion tester (China), an SDTA851e thermal gravimetric analyzer (Switzerland), a KDB-III COD microwave digestion instrument (China), a JSM-7610F scanning electron microscope (Japan), and a D8 Advance X-ray powder diffractometer (Germany).

\subsection{Synthesis of polysuccinimide (PSI) and polyaspartic acid (PASP)}

PSI and PASP were synthesized according to a previous method. ${ }^{28}$ In brief, PSI was obtained via the polycondensation of maleic anhydride and urea, which underwent a dehydration process for $3 \mathrm{~h}$ at $160{ }^{\circ} \mathrm{C}$ after the addition of a mixture of acids $\left(\mathrm{H}_{3} \mathrm{PO}_{4}: \mathrm{H}_{2} \mathrm{SO}_{4}=1: 1\right)$. Then, $10 \% \mathrm{NaOH}$ solution was added to the PSI suspension, and the reaction was carried out at $60{ }^{\circ} \mathrm{C}$ under magnetic stirring for $24 \mathrm{~h}$. Subsequently, the mixture was added to absolute ethanol to generate a precipitate. Finally, after drying, PASP was obtained. The relevant synthesis reactions are illustrated in Scheme 1.

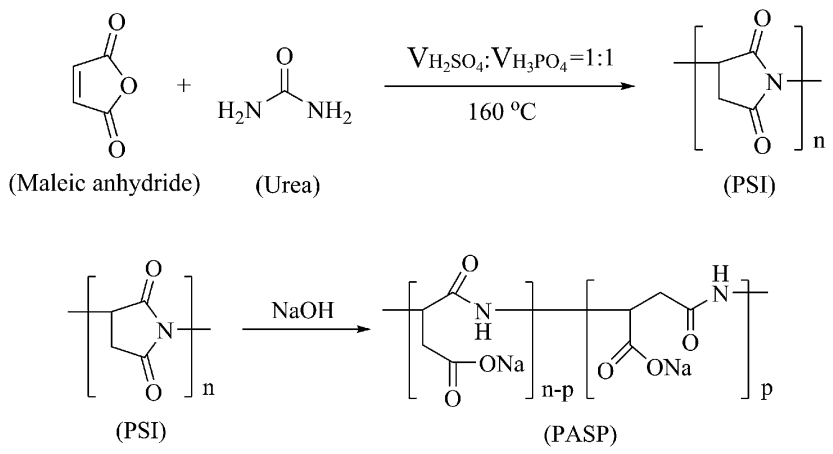

Scheme 1 Synthesis route of PSI and PASP.

\subsection{Synthesis of modified polyaspartic acid (PASP/AMP)}

Herein, $0.8 \mathrm{~g}$ of PSI, $0.58 \mathrm{~g}$ AMP, $8 \mathrm{~mL}$ of distilled water, and 2 $\mathrm{mL}$ of $10 \% \mathrm{NaOH}$ solution were mixed in a round-bottom flask. After heating at $60{ }^{\circ} \mathrm{C}$ under magnetic stirring for $24 \mathrm{~h}$, the $\mathrm{pH}$ of the solution was adjusted to 7-8 using $\mathrm{HCl}$ solution. Then, the solution was poured into a beaker containing $50 \mathrm{~mL}$ ethanol and left standing to allow precipitation. After the supernatant was removed, $10 \mathrm{~mL}$ of distilled water was added. The product was dried at $80{ }^{\circ} \mathrm{C}$ in a drying oven for $12 \mathrm{~h}$ to yield PASP/AMP as a brown solid. The relevant synthetic reaction is shown in Scheme 2.

\subsection{Static test for scale inhibition efficiency}

The static test, which was previously described elsewhere ${ }^{29}$ was performed according to the Chinese National Standard (GB/T 16632-2008). The remaining $\mathrm{Ca}^{2+}$ in the supernatant was detected using an EDTA standard solution in the inhibition experiment against $\mathrm{CaCO}_{3}$ and $\mathrm{CaSO}_{4}$, whereas in the inhibition experiment against $\mathrm{Ca}_{3}\left(\mathrm{PO}_{4}\right)_{2}$, the content of $\mathrm{PO}_{4}{ }^{3-}$ was determined via a $723 \mathrm{~N}$ grating spectrophotometer at $710 \mathrm{~nm}$ using the phosphomolybdic blue spectrophotometric method.

\subsection{Weight loss test for corrosion inhibition efficiency}

The weight loss test was carried out as previously described, ${ }^{\mathbf{3 0}}$ which was conducted to determine the corrosion inhibition

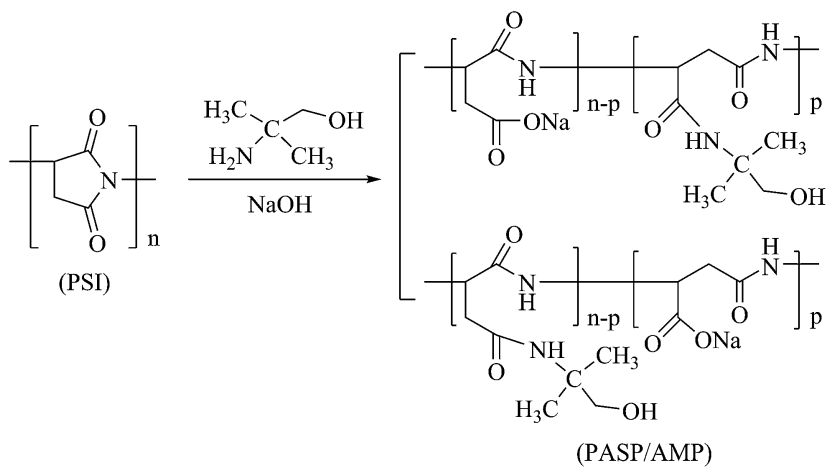

Scheme 2 Synthesis route of the PASP/AMP graft copolymer. 
efficiency of PASP/AMP using a rotary coupon corrosion tester according to the Chinese National Standard (GB/T 18175-2014).

\subsection{Test for biodegradability}

Herein, $100 \mathrm{~g}$ plant growth soil was added to $1 \mathrm{~L}$ distilled water and mixed. After standing for $3 \mathrm{~h}$, the supernatant was obtained as the inoculation fluid. Subsequently, $1 \mathrm{~L}$ distilled water was subjected to an aeration process using an oil-free air pump until the dissolved oxygen content reached a value of $8 \mathrm{mg} \mathrm{L}^{-1}$. After this, $8.5 \mathrm{mg}$ of $\mathrm{KH}_{2} \mathrm{PO}_{4}, 21.8 \mathrm{mg}$ of $\mathrm{K}_{2} \mathrm{HPO}_{4} \cdot 3 \mathrm{H}_{2} \mathrm{O}, 44.6 \mathrm{mg}$ of $\mathrm{Na}_{2} \mathrm{HPO}_{4} \cdot 12 \mathrm{H}_{2} \mathrm{O}, 1.7 \mathrm{mg}$ of $\mathrm{NH}_{4} \mathrm{Cl}, 11.0 \mathrm{mg}$ of $\mathrm{MgSO}_{4}, 27.6 \mathrm{mg}$ of $\mathrm{CaCl}_{2}$, and $0.3 \mathrm{mg}$ of $\mathrm{FeCl}_{3} \cdot 6 \mathrm{H}_{2} \mathrm{O}$ were added to the aerated liquid to obtain dilution water. A certain amount of PASP/AMP, $30 \mathrm{~mL}$ of inoculation fluid, and $270 \mathrm{~mL}$ of dilution water were successively added to a $500 \mathrm{~mL}$ serum bottle. Then, the serum bottle was placed in a constant temperature incubator at $25^{\circ} \mathrm{C}$, and a blank experiment was carried out at the same time. Then, the COD value of the solution was determined on day 1, 7, 14, 21 , and 28 . The biodegradation rate $(\eta)$ was calculated using the following formula:

$$
\eta=\left(1-\frac{C_{t}-C_{\mathrm{bt}}}{C_{0}-C_{\mathrm{b} 0}}\right) \times 100 \%
$$

where $C_{t}$ stands for the COD value in the solution containing PASP/AMP on day $t$ and $C_{\mathrm{b} t}$ is that of the blank experiment; $C_{0}$ is the original COD value of the solution containing PASP/AMP, and $C_{\mathrm{bo}}$ is that of the blank experiment.

\section{Results and discussion}

\section{$3.1{ }^{1} \mathrm{H}$ NMR characterization of PASP/AMP}

Fig. 1 displays the ${ }^{1} \mathrm{H}$ NMR spectrum of PASP/AMP in $\mathrm{D}_{2} \mathrm{O}$. The signals at $\delta_{\mathrm{H}}=4.36$ (a) and $\delta_{\mathrm{H}}=2.63$ (b) are assigned to $-\mathrm{CH}-$ and $-\mathrm{CH}_{2}-$ on the main chain, respectively. In addition, the signals at $\delta_{\mathrm{H}}=3.47$ (c) and $\delta_{\mathrm{H}}=1.18$ (d) are ascribed to $-\mathrm{CH}_{2}-$

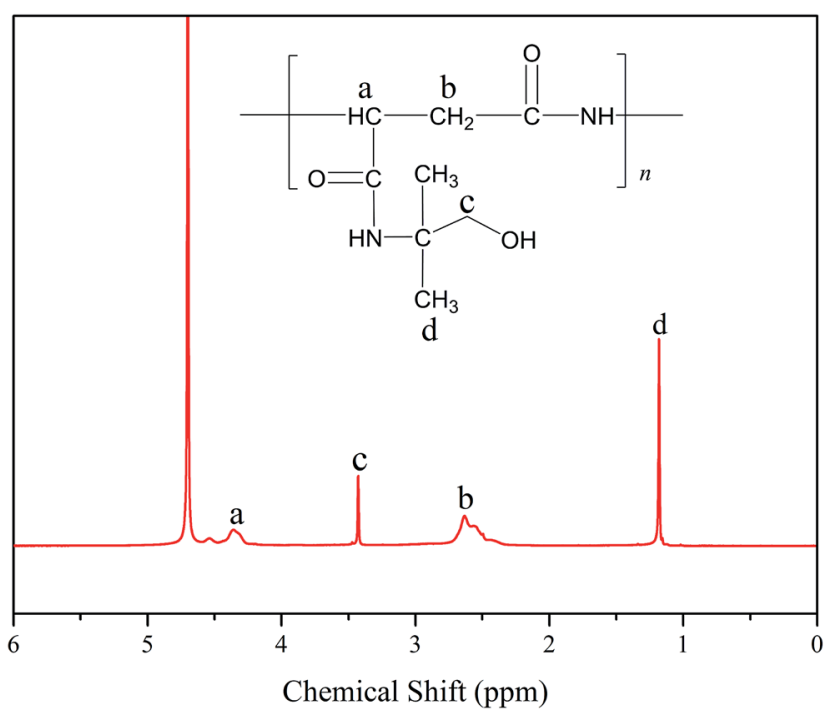

Fig. $1{ }^{1} \mathrm{H}$ NMR spectrum of PASP/AMP. and $-\mathrm{CH}_{3}$ on the side chain, respectively, which indicate the successful synthesis of the PASP/AMP graft copolymer.

\subsection{FTIR characterization of PASP/AMP}

The FTIR spectrum of PASP/AMP is shown in Fig. 2. It can be seen that the characteristic absorption peak of the $\mathrm{N}-\mathrm{H}$ bond stretching vibration appears at $3413 \mathrm{~cm}^{-1}$, and $1597 \mathrm{~cm}^{-1}$ is the stretching vibration absorption peak of the $\mathrm{C}=\mathrm{O}$ bond of the amide; the absorption peak at $1400 \mathrm{~cm}^{-1}$ is attributed to the vibration of $\mathrm{N}-\mathrm{H}$ bond bending and $\mathrm{C}-\mathrm{N}$ bond stretching in $-\mathrm{CONH}$, and the absorption peak at $1059 \mathrm{~cm}^{-1}$ is the characteristic absorption peak of -OH. Thus, it can be inferred that the PASP/AMP graft copolymer has been successfully synthesized.

\subsection{Thermogravimetric analysis (TGA)}

Thermogravimetric analysis was employed to examine the thermal stability of the samples in a nitrogen atmosphere. The test was conducted at $25-800{ }^{\circ} \mathrm{C}$ at a heating rate of $10^{\circ} \mathrm{C} \mathrm{min}{ }^{-1}$. According to Fig. 3, PASP and PASP/AMP showed similar thermal weight loss behaviors with little mass loss below $100{ }^{\circ} \mathrm{C}$. In the TGA thermogram of PASP/AMP, no significant reduction is observed as compared to that of PASP; this indicates that its thermal stability is as good as that of PASP. Furthermore, the thermal degradation of PASP/AMP occurred above $200{ }^{\circ} \mathrm{C}$, indicating that it is well suited for cooling water systems.

\subsection{Inhibition performance against $\mathrm{CaCO}_{3}$}

3.4.1 Influence of concentration on inhibition efficiency against $\mathrm{CaCO}_{3}$. Fig. 4 reveals the influence of different concentrations of both inhibitors on scale inhibition against $\mathrm{CaCO}_{3}$. It can be seen that the inhibition efficiency increased with the increasing concentration of both inhibitors. The scale inhibition efficiency of PASP/AMP reached up to $94 \%$ at $0.75 \mathrm{mg}$ $\mathrm{L}^{-1}$, whereas that of PASP was $88 \%$. The maximum inhibition

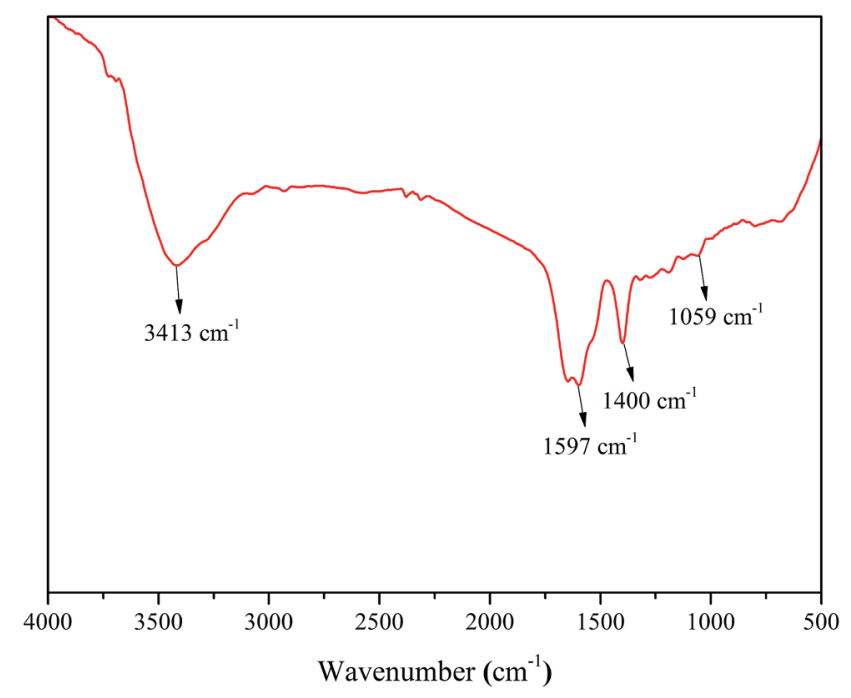

Fig. 2 FTIR spectrum of PASP/AMP. 


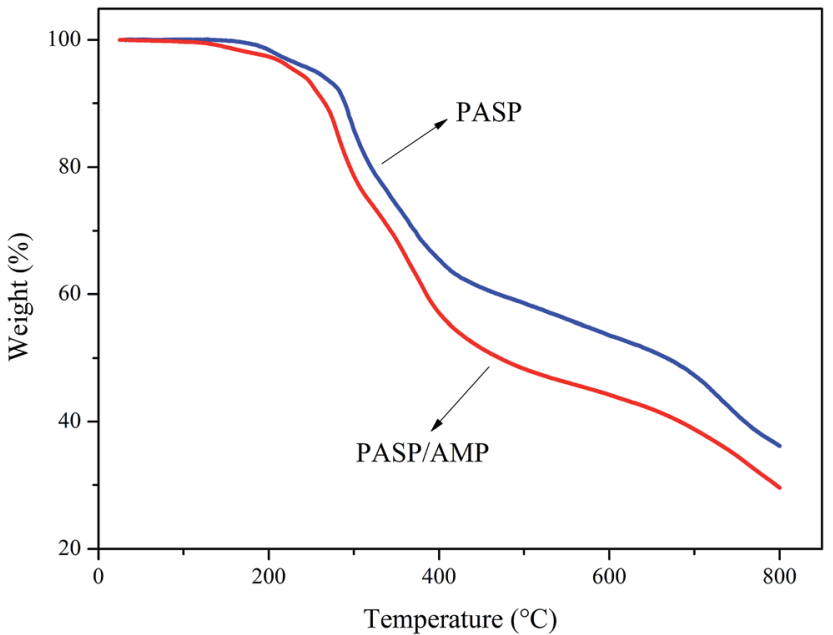

Fig. 3 Thermogravimetric analysis curves of PASP and PASP/AMP.

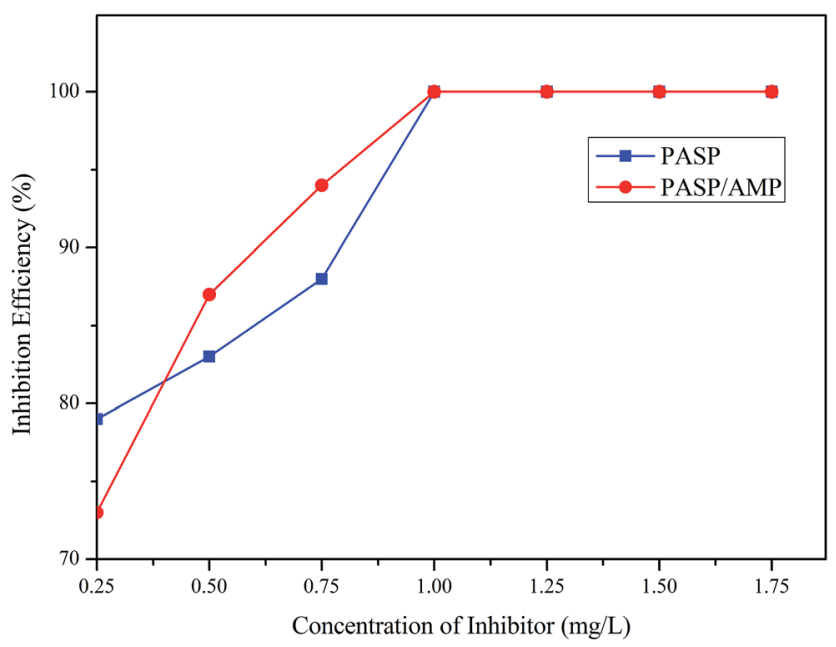

Fig. 4 Influence of concentration on inhibition efficiency against $\mathrm{CaCO}_{3}\left(\mathrm{Ca}^{2+}: 250 \mathrm{mg} \mathrm{L}^{-1}, \mathrm{HCO}_{3}{ }^{-}: 250 \mathrm{mg} \mathrm{L}^{-1}, \mathrm{~T}: 80^{\circ} \mathrm{C}\right.$, and $\left.t: 6 \mathrm{~h}\right)$.

efficiency of PASP/AMP was about $100 \%$ at $1 \mathrm{mg} \mathrm{L}{ }^{-1}$, and the inhibition efficiency remained constant beyond $1 \mathrm{mg} \mathrm{L}^{-1}$.

3.4.2 Influence of $\mathrm{Ca}^{2+}$ concentration on inhibition efficiency against $\mathrm{CaCO}_{3}$. Fig. 5 shows the influence of $\mathrm{Ca}^{2+}$ concentration on inhibition efficiency against $\mathrm{CaCO}_{3}$. For PASP/ AMP, the inhibition efficiency remained at $100 \%$ when the $\mathrm{Ca}^{2+}$ concentration was less than $400 \mathrm{mg} \mathrm{L}^{-1}$. Although the inhibition efficiency decreased an increase in the $\mathrm{Ca}^{2+}$ concentration above $400 \mathrm{mg} \mathrm{L}^{-1}$, it still showed a better performance than that of PASP. The inhibition efficiency of PASP/AMP was $70 \%$ at $550 \mathrm{mg} \mathrm{L}^{-1}$, whereas that of PASP dropped to $47 \%$. This could be ascribed to the fact that hydroxyl on the side chain played a vital role in the adsorption of $\mathrm{Ca}^{2+}$, and the equilibrium $\mathrm{Ca}^{2+}+$ $2 \mathrm{HCO}_{3}{ }^{-} \rightarrow \mathrm{CaCO}_{3}+\mathrm{CO}_{2}+\mathrm{H}_{2} \mathrm{O}$ was restrained. ${ }^{31}$

3.4.3 Influence of heating time on the inhibition efficiency against $\mathrm{CaCO}_{3}$. The influence of heating time on the inhibition efficiency against $\mathrm{CaCO}_{3}$ is shown in Fig. 6. Clearly, the variation in the heating time had little impact on the inhibition

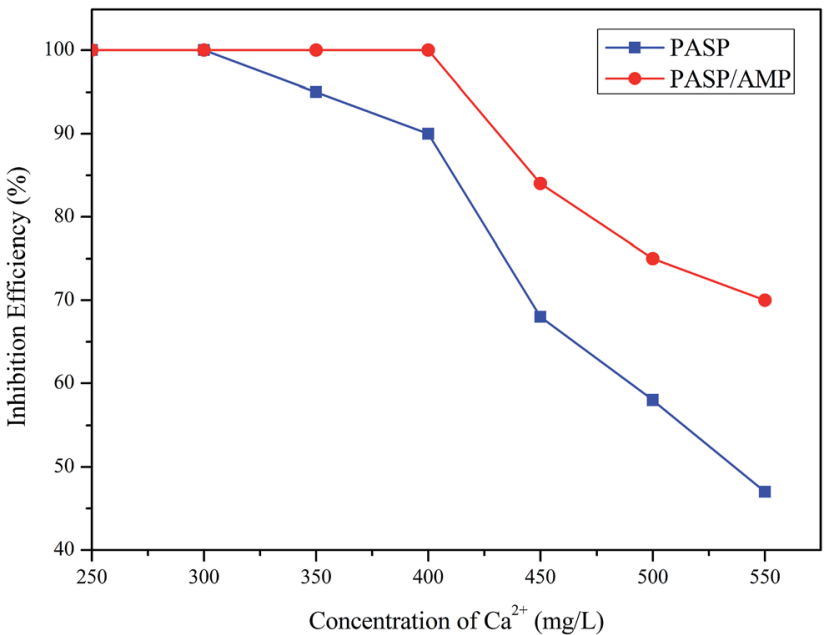

Fig. 5 Influence of $\mathrm{Ca}^{2+}$ concentration on inhibition efficiency against $\mathrm{CaCO}_{3}\left(\mathrm{Ca}^{2+}: 250-550 \mathrm{mg} \mathrm{L}^{-1}, \mathrm{HCO}_{3}^{-}: 250-550 \mathrm{mg} \mathrm{L}^{-1}, \mathrm{~T}: 80^{\circ} \mathrm{C}, \mathrm{t}\right.$ : $6 \mathrm{~h}$, PASP/AMP: $1 \mathrm{mg} \mathrm{L}^{-1}$, and PASP: $1 \mathrm{mg} \mathrm{L}^{-1}$ ).

efficiency of PASP/AMP, and the inhibition efficiency remained almost $100 \%$ when PASP/AMP was heated for less than $16 \mathrm{~h}$. After this, the inhibition efficiency started to fall with an increase in time. For PASP, the inhibition efficiency obviously declined when it was heated for more than $10 \mathrm{~h}$. The promotion of the inhibition efficiency of PASP/AMP can be attributed to the presence of hydroxyl groups and the formation of a more stable structure with $\mathrm{Ca}^{2+}$ that is not destroyed even under long heating time conditions. ${ }^{32}$

\subsection{Inhibition performance against $\mathrm{CaSO}_{4}$}

Fig. 7 displays the inhibition efficiency of PASP and PASP/AMP against $\mathrm{CaSO}_{4}$. The inhibition performance of PASP/AMP was superior to that of PASP at a concentration of $4 \mathrm{mg} \mathrm{L}^{-1}$. The maximum inhibition efficiency of $100 \%$ was obtained at $4 \mathrm{mg}$

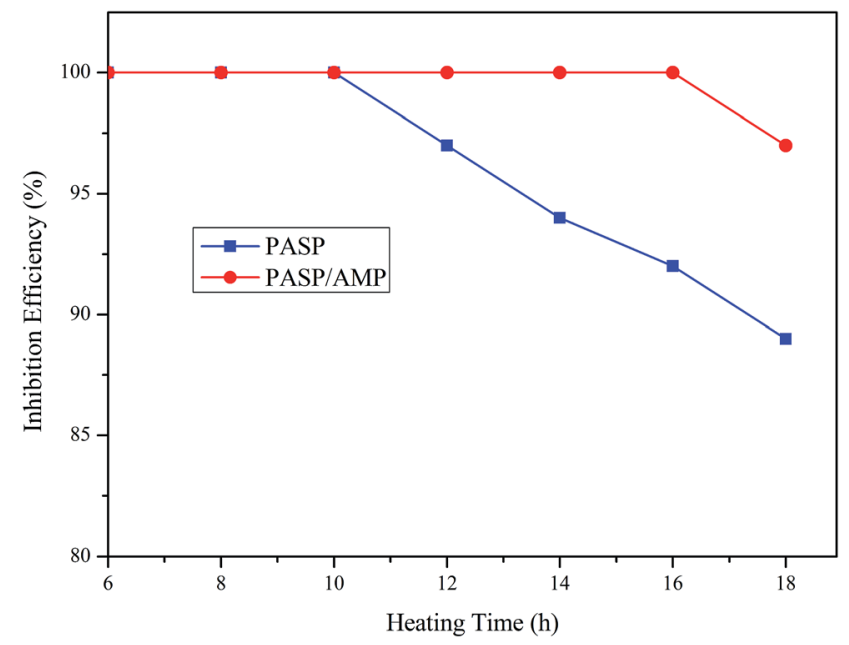

Fig. 6 Influence of heating time on inhibition efficiency against $\mathrm{CaCO}_{3} \mathrm{CCa}^{2+}: 250 \mathrm{mg} \mathrm{L}^{-1}, \mathrm{HCO}_{3}^{-}: 250 \mathrm{mg} \mathrm{L}^{-1}, \mathrm{~T}: 80{ }^{\circ} \mathrm{C}, \mathrm{t}: 6-18 \mathrm{~h}$, PASP/AMP: $1 \mathrm{mg} \mathrm{L}^{-1}$, and PASP: $1 \mathrm{mg} \mathrm{L}^{-1}$ ). 


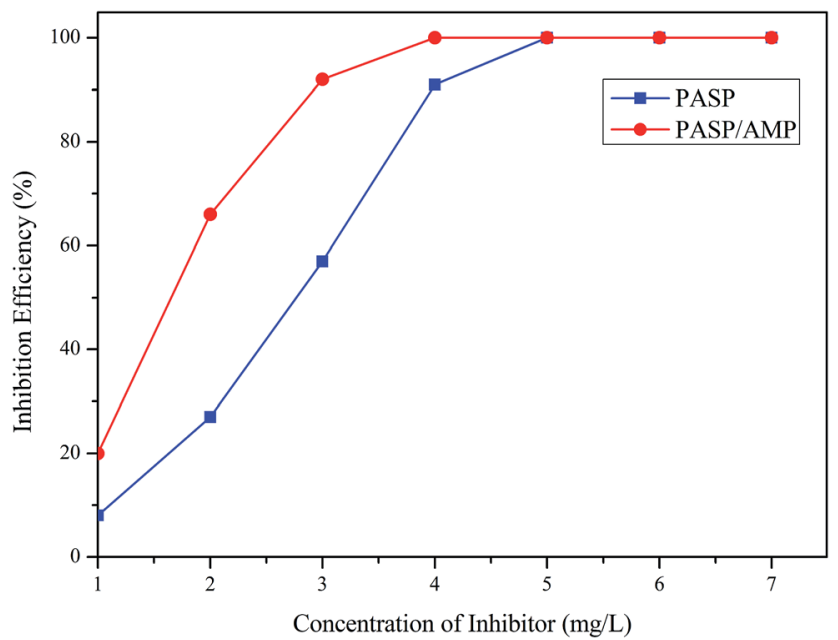

Fig. 7 Inhibition efficiency against $\mathrm{CaSO}_{4}\left(\mathrm{Ca}^{2+}: 6800 \mathrm{mg} \mathrm{L}^{-1}, \mathrm{SO}_{4}{ }^{2-}\right.$ : $7100 \mathrm{mg} \mathrm{L}^{-1}, \mathrm{~T}: 70^{\circ} \mathrm{C}$, and $t: 6 \mathrm{~h}$ ).

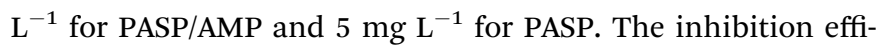
ciency of PASP/AMP remained unchanged when the concentration was greater than $4 \mathrm{mg} \mathrm{L}^{-1}$. This may be because hydroxyl on the side chain helped PASP/AMP absorb on the nuclei surface of $\mathrm{CaSO}_{4}$, and then, the scale was wrapped, which delayed the growth of the scale. ${ }^{33}$

\subsection{Inhibition performance against $\mathrm{Ca}_{3}\left(\mathrm{PO}_{4}\right)_{2}$}

The inhibition performance of PASP and PASP/AMP against $\mathrm{Ca}_{3}\left(\mathrm{PO}_{4}\right)_{2}$ was investigated, as shown in Fig. 8. The inhibition efficiency of PASP/AMP gradually increased with an increase in concentration. The inhibition efficiency of PASP/AMP achieved was as high as $74 \%$ at $10 \mathrm{mg} \mathrm{L}^{-1}$, whereas that of PASP was only $19 \%$. Furthermore, the inhibition efficiency of PASP/AMP reached up to $100 \%$ at $14 \mathrm{mg} \mathrm{L}^{-1}$, which was far greater than that of PASP. Consequently, the introduction of functional

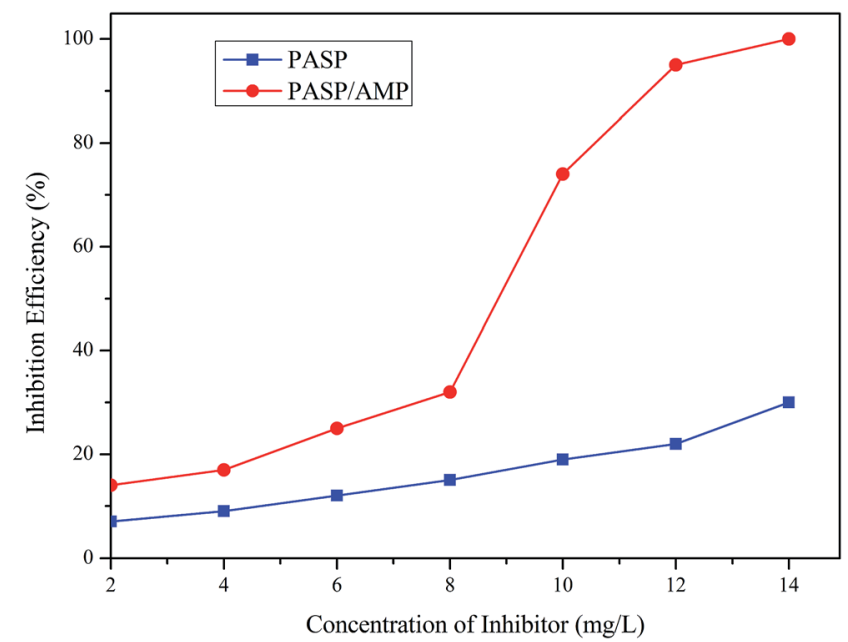

Fig. 8 Inhibition efficiency against $\mathrm{Ca}_{3}\left(\mathrm{PO}_{4}\right)_{2}\left(\mathrm{Ca}^{2+}: 250 \mathrm{mg} \mathrm{L}^{-1}\right.$, $\mathrm{PO}_{4}{ }^{3-}: 10 \mathrm{mg} \mathrm{L}^{-1}, \mathrm{~T}: 80^{\circ} \mathrm{C}$, and $t: 10 \mathrm{~h}$ ). groups promoted the inhibition performance of PASP against $\mathrm{Ca}_{3}\left(\mathrm{PO}_{4}\right)_{2}$.

\subsection{Corrosion inhibition performance}

Fig. 9 demonstrates the influence of the concentration of PASP and PASP/AMP on the corrosion inhibition efficiency. It is worthy to point out that the corrosion inhibition efficiency of PASP/AMP reaches up to $28 \%$ at $24 \mathrm{mg} \mathrm{L}^{-1}$, whereas for PASP, the corrosion inhibition efficiency only reaches $21 \%$ at the same concentration. This was because the introduction of polar groups into the copolymer facilitated adsorption of the copolymer onto the surface of the metal, and then, the non-polar part facilitated the formation of a hydrophobic membrane, which blocked charge transfer and altered the interfacial properties. ${ }^{34}$ Furthermore, contact between the metal and corrosive substance was prevented; therefore, corrosion was effectively suppressed.

\subsection{Biodegradation performance}

As is shown in Fig. 10, the biodegradation rate of PASP and PASP/AMP increased with time. On the 28th day, the biodegradation rate of PASP was $81 \%$, whereas that of PASP/AMP was $65 \%$. According to the Convention for the Protection of the Marine Environment of the North-East Atlantic, a polymer is considered readily biodegradable if its biodegradation rate is greater than $60 \%$ within 28 days. ${ }^{35}$ Therefore, PASP/AMP is eligible to be listed as a biodegradable copolymer of PASP despite the existence of functional groups on its side chain. The biodegradation behavior of PASP/AMP is lower than that of PASP. This decrease can be attributed to the presence of $\beta$ amide units or d-aspartic acid units that blocked further biodegradation, and the more irregular end group may also affect the rate. ${ }^{36}$

\subsection{SEM analysis of $\mathrm{CaCO}_{3}, \mathrm{CaSO}_{4}$, and $\mathrm{Ca}_{3}\left(\mathrm{PO}_{4}\right)_{2}$}

The morphologies of $\mathrm{CaCO}_{3}, \mathrm{CaSO}_{4}$, and $\mathrm{Ca}_{3}\left(\mathrm{PO}_{4}\right)_{2}$ were surveyed via SEM (Fig. 11). The $\mathrm{CaCO}_{3}$ deposit had a compact

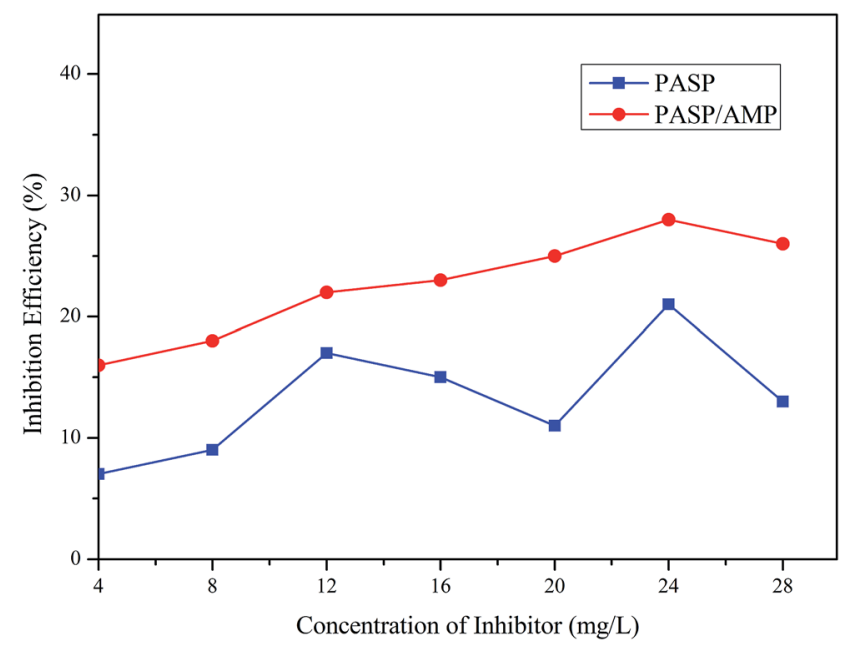

Fig. 9 Corrosion inhibition efficiency of PASP and PASP/AMP. 


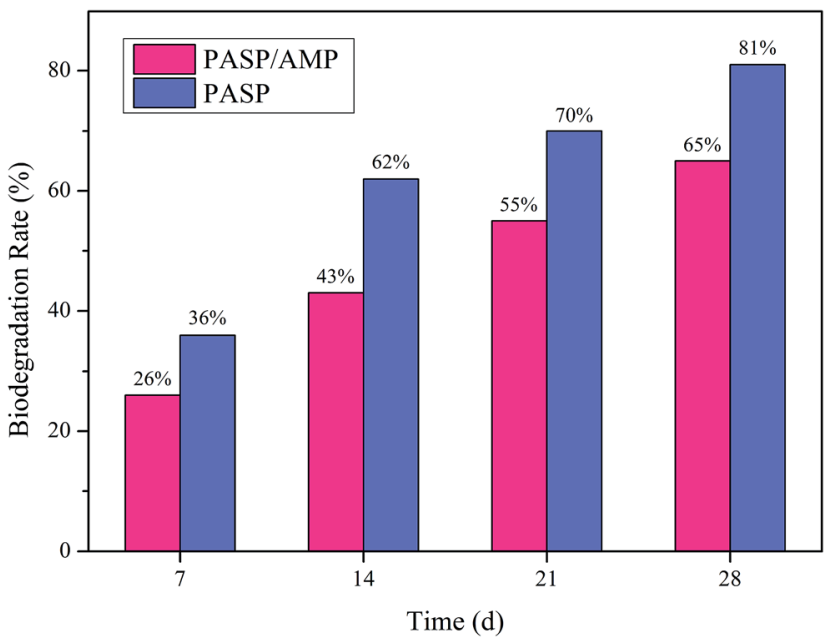

Fig. 10 Biodegradation rate of PASP and PASP/AMP.

structure with a regular arrangement, and the $\mathrm{CaSO}_{4}$ crystals displayed a needle-like shape with a glossy surface in the absence of PASP/AMP. However, the structure of $\mathrm{CaCO}_{3}$ and
$\mathrm{CaSO}_{4}$ became fragmented and tended to be irregular in the presence of PASP/AMP. With the addition of PASP/AMP, the structure of the $\mathrm{Ca}_{3}\left(\mathrm{PO}_{4}\right)_{2}$ scale changed from dense layered to agglomerated and became looser. In other words, PASP/AMP can adsorb on the surface of the crystal and block the growth of the crystal, thus destroying the morphology of the deposit. ${ }^{37}$ As a result, the scale showed poor adhesion to the inner wall of the pipe and was easily dispersed by flowing water.

\subsection{XRD analysis of $\mathrm{CaCO}_{3}, \mathrm{CaSO}_{4}$, and $\mathrm{Ca}_{3}\left(\mathrm{PO}_{4}\right)_{2}$}

Fig. 12 reveals the XRD spectra of $\mathrm{CaCO}_{3}$ with and without PASP/AMP. In the absence of PASP/AMP, diffraction peaks at $23.07^{\circ}, 29.42^{\circ}, 31.47^{\circ}, 36.00^{\circ}, 39.42^{\circ}, 43.17^{\circ}, 47.51^{\circ}, 48.51^{\circ}$, $57.42^{\circ}, 60.67^{\circ}, 63.09^{\circ}, 64.69^{\circ}$, and $65.65^{\circ}$, belonging to calcite $(\mathrm{PDF}=47-1743)$, and diffraction peaks at $26.22^{\circ}, 27.22^{\circ}, 33.16^{\circ}$, $37.28^{\circ}, 37.91^{\circ}, 38.42^{\circ}, 41.20^{\circ}, 45.86^{\circ}, 50.25^{\circ}, 52.49^{\circ}, 53.04^{\circ}$, and $59.25^{\circ}$ corresponding to aragonite $(\mathrm{PDF}=41-1475)$ were obtained. However, when PASP/AMP was added, the diffraction peaks at $20.95^{\circ}, 24.86^{\circ}, 32.75^{\circ}, 42.73^{\circ}, 43.81^{\circ}, 49.07^{\circ}$, and $55.77^{\circ}$ for vaterite ( $\mathrm{PDF}=33-0268)$ were also observed in addition to those for calcite and aragonite, demonstrating that PASP/AMP affected the crystal orientation and structure of $\mathrm{CaCO}_{3}$.

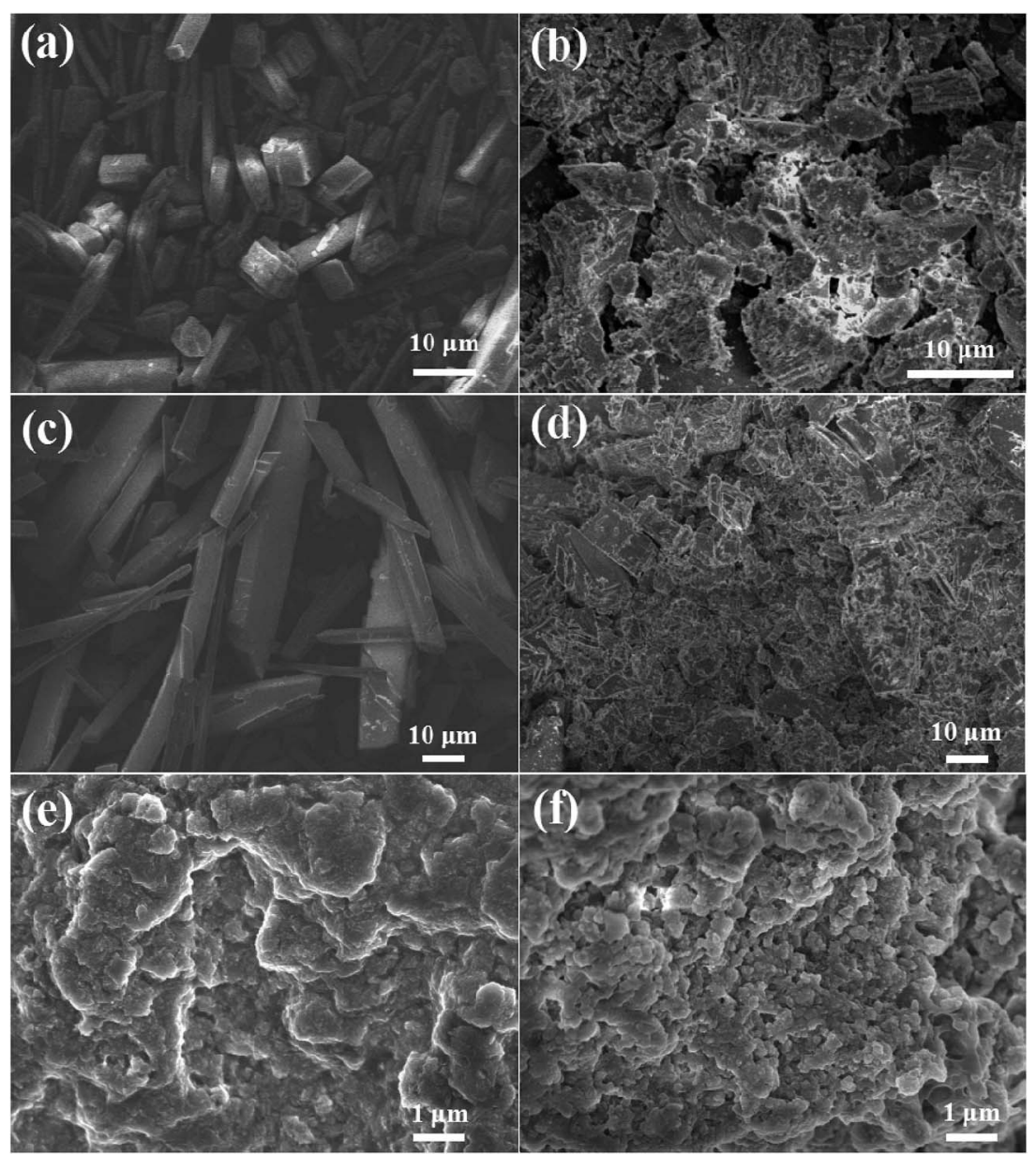

Fig. 11 SEM images of $\mathrm{CaCO}_{3}(\mathrm{a}), \mathrm{CaSO}_{4}(\mathrm{c})$, and $\mathrm{Ca}_{3}\left(\mathrm{PO}_{4}\right)_{2}(\mathrm{e})$ in the absence of PASP/AMP, and $\mathrm{CaCO}_{3}(\mathrm{~b}), \mathrm{CaSO}_{4}(\mathrm{~d}), \mathrm{and} \mathrm{Ca}_{3}\left(\mathrm{PO}_{4}\right)_{2}$ (f) in the presence of PASP/AMP 


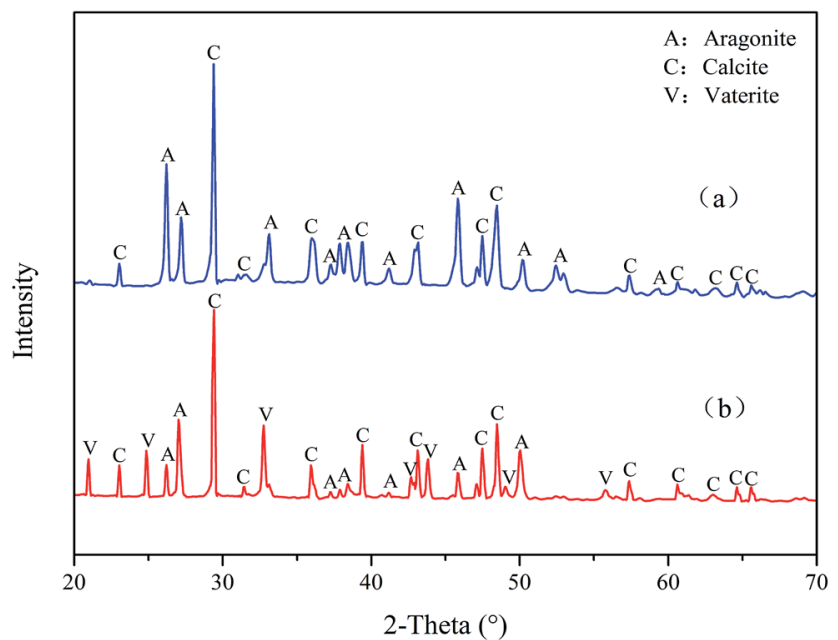

Fig. 12 XRD spectra of $\mathrm{CaCO}_{3}$ without PASP/AMP (a) and with PASP/ AMP (b).

The XRD spectra of $\mathrm{CaSO}_{4}$ with and without PASP/AMP are shown in Fig. 13. The strong diffraction peaks at $11.54^{\circ}, 20.69^{\circ}$, $23.36^{\circ}, 29.07^{\circ}, 31.08^{\circ}$, and $33.32^{\circ}$ are characteristic peaks of $\mathrm{CaSO}_{4} \cdot 2 \mathrm{H}_{2} \mathrm{O}(\mathrm{PDF}=33-0311)$. The diffraction peaks obviously became weaker with the addition of PASP/AMP, which indicated that the introduction of PASP/AMP contributed to the distortion of the $\mathrm{CaSO}_{4}$ precipitate morphology.

Fig. 14 displays the XRD spectra of $\mathrm{Ca}_{3}\left(\mathrm{PO}_{4}\right)_{2}$ in the absence and presence of PASP/AMP. The comparison of (a) and (b) shows that they have similar characteristic peaks, but the intensity of the peaks in (a) is significantly stronger than that in (b). This phenomenon illustrates that the $\mathrm{Ca}_{3}\left(\mathrm{PO}_{4}\right)_{2}$ crystal changed after the addition of PASP/AMP, and the crystallization degree of the $\mathrm{Ca}_{3}\left(\mathrm{PO}_{4}\right)_{2}$ crystals was reduced. According to the XRD analysis, the addition of PASP/AMP destroyed the growth tendency and caused the scale structure to become loose, resulting in the easy removal of the precipitate. ${ }^{38}$

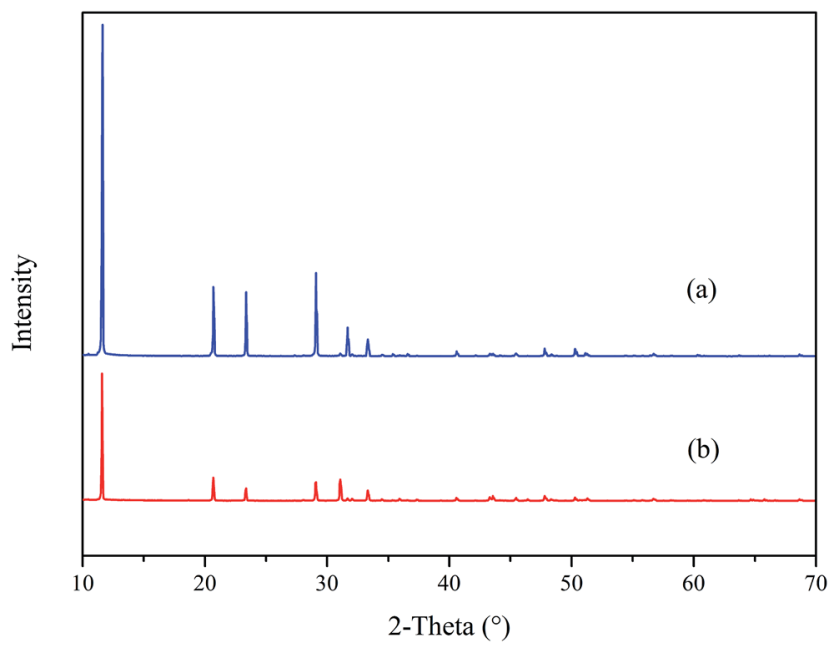

Fig. 13 XRD spectra of $\mathrm{CaSO}_{4}$ without PASP/AMP (a) and with PASP/ AMP (b).

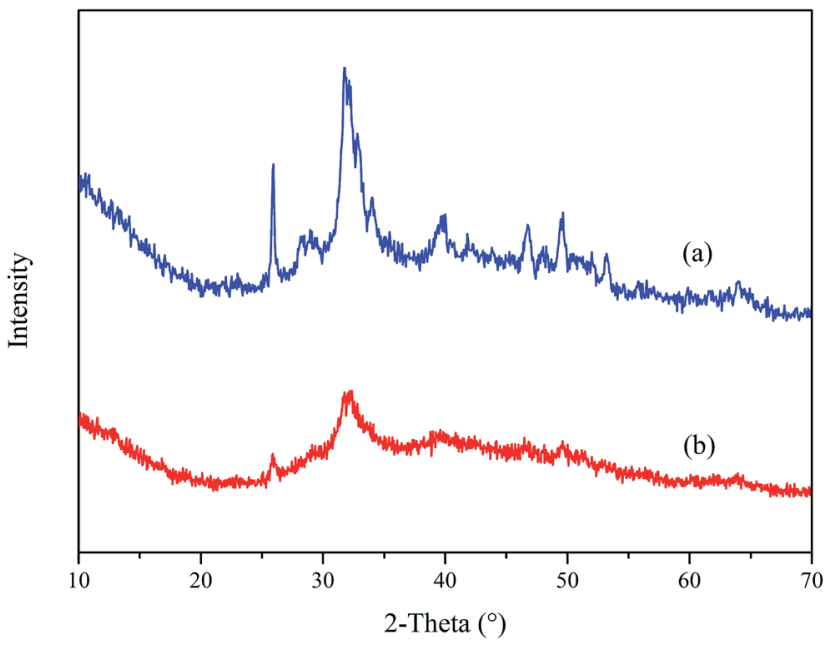

Fig. 14 XRD spectra of $\mathrm{Ca}_{3}\left(\mathrm{PO}_{4}\right)_{2}$ without PASP/AMP (a) and with PASP/AMP (b).

\section{Conclusion}

A novel PASP/AMP graft copolymer has been successfully prepared via a ring-opening reaction using PSI and AMP. The scale and corrosion inhibition performance of the PASP/AMP graft copolymer is enhanced as compared to that of PASP. PASP/AMP exhibits the maximum inhibition efficiency of $100 \%$ against $\mathrm{CaCO}_{3}$ and $\mathrm{CaSO}_{4}$ at 1 and $4 \mathrm{mg} \mathrm{L}^{-1}$, respectively. It is worth noting that the inhibition efficiency of PASP/AMP against $\mathrm{Ca}_{3}\left(\mathrm{PO}_{4}\right)_{2}$ reaches $100 \%$ at $14 \mathrm{mg} \mathrm{L}{ }^{-1}$, which compensates the limitations of PASP. The maximum corrosion inhibition efficiency of PASP/AMP reached $28 \%$ at $24 \mathrm{mg} \mathrm{L}^{-1}$. Moreover, the biodegradation experiment proves that PASP/AMP possesses excellent biodegradability with a biodegradation rate of $65 \%$ in 28 days, which is environmentally acceptable. Subsequently, the SEM and XRD analyses reveal that with the addition of PASP/ AMP, the hard scale deposits are destroyed and transformed into loose dirt that can be removed easily. The introduction of AMP into the side chain drastically strengthened the comprehensive properties of PASP without significantly affecting its biodegradability. Thus, for further modification of PASP, the grafting of uncomplicated structures containing inhibitive functional groups will be instructive.

\section{Acknowledgements}

This work was supported by the funds received from the Henan Province Science \& Technology Bureau (142107000015 and 162102410086).

\section{Notes and references}

1 M. A. Migahed, A. A. Attia and R. E. Habib, $R S C A d v ., 2015,5$, 57254.

2 A. Antony, J. H. Low, S. Gray, A. E. Childress and P. Le-Clech, J. Membr. Sci., 2012, 383, 1. 
3 I. Drela, P. Falewicz and S. Kuczkowska, Water Res., 1998, 32, 3188.

4 R. Touir, N. Dkhireche, M. E. Touhami, M. Sfaira and O. Senhaji, Mater. Chem. Phys., 2010, 122, 1.

5 I. Nishida, Y. Okaue and T. Yokoyama, J. Colloid Interface Sci., 2011, 360, 110.

6 P. B. Raja and M. G. Sethuraman, Mater. Lett., 2008, 62, 113. 7 V. Annibaldi, A. D. Rooney and C. B. Breslin, Corros. Sci., 2012, 59, 179.

8 H. Cheap-Charpentier, D. Gelus, N. Pécoul, H. Perrot and J. Lédion, J. Cryst. Growth, 2016, 443, 43.

9 H. H. Huang, Q. Yao, H. L. Chen and B. L. Liu, RSC Adv., 2015, 5, 92943.

10 D. E. Abd-El-Khalek and B. A. Abd-El-Nabey, Desalination, 2013, 311, 227.

11 M. A. Deyab, Desalination, 2016, 384, 60.

12 H. X. Zhang, F. Wang, X. H. Jin and Y. C. Zhu, Desalination, 2013, 326, 55.

13 X. H. Qiang, Z. H. Sheng and H. Zhang, Desalination, 2013, 309, 237.

14 I. Sekine, T. Shimode, M. Yuasa and K. Takaoka, Ind. Eng. Chem. Res., 1990, 29, 1460.

15 O. Horner, H. Cheap-Charpentier, X. Cachet, H. Perrot and J. Lédion, Desalination, 2017, 409, 157.

16 A. A. Younes, H. H. El-Maghrabi and H. R. Ali, J. Hazard. Mater., 2017, 334, 1.

17 Y. M. Al-Roomi, K. F. Hussain and M. Al-Rifaie, Desalination, 2015, 375, 138.

18 M. A. Deyab, J. Ind. Eng. Chem., 2015, 22, 384.

19 F. S. de Souza and A. Spinelli, Corros. Sci., 2009, 51, 642.

20 A. Ketsetzi, A. Stathoulopoulou and K. D. Demadis, Desalination, 2008, 223, 487.

21 A. Martinod, A. Neville, M. Euvrad and K. Sorbie, Chem. Eng. Sci., 2009, 64, 2413.
22 C. J. He, Z. P. Tian, B. R. Zhang, Y. Lin and X. Chen, Ind. Eng. Chem. Res., 2015, 54, 1971.

23 R. B. Fu, D. D. Wen, X. Q. Xia, W. Zhang and Y. Y. Gu, Chem. Eng. J., 2017, 316, 601.

24 J. X. Chen, L. H. Xu, J. Han, M. Su and Q. Wu, Desalination, 2015, 358, 42.

25 Y. H. Gao, L. H. Fan, L. Ward and Z. F. Liu, Desalination, 2015, 365, 220.

26 Y. Zhang, H. Q. Yin, Q. S. Zhang, Y. Z. Li and P. J. Yao, Desalination, 2016, 395, 92.

27 J. Y. Feng, L. J. Gao, R. Z. Wen, Y. Y. Deng and X. J. Wu, Desalination, 2014, 345, 72.

28 Y. Xu, L. L. Zhao, L. N. Wang, S. Y. Xu and Y. C. Cui, Desalination, 2012, 286, 285.

29 B. Zhang, D. P. Zhou, X. G. Lv, Y. Xu and Y. C. Cui, Desalination, 2013, 327, 32.

30 B. Zhang, J. Li, X. G. Lv, Y. C. Cui and Y. Xu, Desalin. Water Treat., 2015, 54, 1998.

31 B. K. Pramanik, Y. H. Gao, L. H. Fan, F. A. Roddick and Z. F. Liu, Desalination, 2017, 404, 224.

32 Y. Xu, B. Zhang, L. L. Zhao and Y. C. Cui, Desalination, 2013, 311, 156.

33 S. C. Shi, X. W. Zhao, Q. Wang, H. T. Shan and Y. Xu, RSC $A d v .$, 2016, 6, 102406.

34 M. A. Migahed, S. M. Rashwan, M. M. Kamel and R. E. Habib, J. Mol. Liq., 2016, 224, 849.

35 D. Hasson, H. Shemer and A. Sher, Ind. Eng. Chem. Res., 2011, 50, 7601.

36 T. Nakato, M. Yoshitake, K. Matsubara, M. Tomida and T. Kakuchi, Macromolecules, 1998, 31, 2107.

37 D. Liu, W. B. Dong, F. T. Li, F. Hui and J. Lédion, Desalination, 2012, 304, 1.

38 H. F. Wang, M. D. Gao, Y. Guo, Y. F. Yang and R. B. Hu, Desalination, 2016, 398, 198. 